\title{
Phase variation of the opacity outer membrane protein controls invasion by Neisseria gonorrhoeae into human epithelial cells
}

\section{Sou-ichi Makino, Jos P.M.van Putten and Thomas F.Meyer}

Max-Planck-Institut für Biologie, Abteilung Infektionsbiologie, Spemannstrasse 34, D-7400 Tübingen, FRG

Communicated by T.F.Meyer

Neisseria gonorrhoeae is a facultative intracellular bacterium capable of penetrating into certain human epithelial cell types. In order to identify gonococcal factors essential for invading Chang human conjunctiva cells, a gentamicin selection assay for the quantification of viable intracellular bacteria was used in conjunction with microscopy. The results demonstrate a correlation between the invasive behaviour of gonococci and the expression of Opa proteins, a family of variable outer membrane proteins present in all pathogenic Neisseria species. However, only particular Opa proteins supported invasion into Chang cells as indicated by the use of two unrelated gonococcal strains. Invasion was sensitive to cytochalasin $D$, and strong adherence mediated by the Opa proteins appeared to be essential for the internalization of gonococci. In contrast pili, which also conferred binding to Chang conjunctiva cells, did not support cellular invasion but rather were inhibitory. Key words: bacterial adherence/gonococci/intracellular parasites/phase and antigenic variation/piliation

\section{Introduction}

The early stages of an infection with Neisseria gonorrhoeae, the causative agent of gonorrhoea in humans, are governed by specific receptor-mediated interactions between the pathogen and epithelial tissues. An important factor in these processes are the pili, fine hair-like structures protruding from the gonococcal surface. Pili are composed of the major subunit, pilin (Meyer et al., 1984; Hagblom et al., 1985), and possibly additional minor subunits (Muir et al., 1988; Parge et al., 1990). They mediate the initial attachment of gonococci to human epithelial cells in a species and tissue specific manner, which is eventually followed by an endocytic internalization by epithelial tissues (McGee et al., 1983, Tjia et al., 1988). The interaction between gonococci and professional phagocytes, e.g. polymorphonuclear phagocytes and monocytes (Rest and Shafer, 1989; Virji and Heckels, 1986) is in some regard reminiscent of epithelial cell invasion. While gonococci are efficiently phagocytosed, some internalized gonococci are able to avoid intracellular killing (Parsons et al., 1986). Gonococci may thus be regarded as facultative intracellular parasites.

The exact nature of the pathogen and host cell factors involved in epithelial invasion have not been identified. Microscopy studies indicate that tight attachment of the pathogen to the epithelial membrane, probably conferred by outer membrane adhesins, is essential for the initiation of the invasion process (McGee et al., 1983; J.F.L.Weel et al., 1991). Although pili confer binding to epithelial cells, their contribution to cellular invasion is unknown. Several other adhesins have been detected on the gonococcal surface, the best studied example of which is a $36 \mathrm{kd}$ adhesin with binding properties for gangliotetrasylceramide, a glycolipid abundant in a variety of tissues (Strömberg et al., 1988; Paruchuri et al., 1990). Other putative binding factors from $N$.gonorrhoeae for human cells include a glycolipid binding protein that is also associated with Neisseria subflava (Nyberg et al., 1990) and a $65 \mathrm{kd}$ outer membrane protein complex (Perrollet and Guinet, 1986). Finally, a family of gonococcal outer membrane proteins, the opacity proteins (Opa, previously P.II), confer adhesion to various human cell types. From many studies it appears that particular Opas may confer an increased adherence to certain epithelial cell types (Lambden et al., 1979; Swanson, 1977). Likewise, distinct Opa proteins have been associated with the binding of gonococci to leukocytes (Rest et al., 1982; King and Swanson, 1978). In addition, some gonococcal Opas that lead to a pronounced colony opacity, function as intergonococcal adhesins conferring binding to the oligosaccharide part of the lipopolysaccharide on neighbouring gonococci (Blake, 1985).

Both pili and Opa are subject to phase and antigenic variation, giving rise to heterogeneous cultures (for review see Meyer et al., 1990). A proportion of a gonococcal culture will always be expected to produce structurally altered pili and Opa, or to have turned on or off the production of these proteins. The genetic mechanisms underlying this phenomenon have been studied in detail and shown to differ for pili and Opa. Both variation systems rely on multiple variant genes in the gonococcal chromosome (Meyer et al., 1982; Stern et al., 1984). Pilin variation occurs by RecAdependent homologous recombination between several variant silent gene copies (pilS) and the expressed pilin gene (pilE; Haas and Meyer, 1986; Swanson et al., 1985; Koomey et al., 1987). In contrast Opa variation occurs by RecA-independent rearrangements in the coding repeat sequence $(\mathrm{CR})$, which undergoes translational reading frame shifts by changing the number of repeat units (Stern et al., 1986; Murphy et al., 1989). These changes occur independently in each of the opa genes, explaining why a single gonococcal cell can produce several different Opa proteins simultaneously.

Cellular invasion by $N$.gonorrhoeae has previously been studied using various organ and cell culture models (McGee et al., 1983; Tjia et al., 1988). We have adopted a cell culture system with the Chang human conjunctiva line (Virji and Everson, 1981) in order to identify the gonococcal factors involved in epithelial cell invasion. The antibiotic gentamicin $(\mathrm{Gm})$, which elicits only poor activity inside eukaryotic cells, has proven efficient in discriminating between intracellular and extracellular bacteria in several 
systems (Isberg and Falkow, 1985; Isberg et al., 1987). By combining Gm selection with microscopy, we demonstrate that the invasive capacity of N.gonorrhoeae is determined by phase transitions in the expression of Opa proteins. Gonococcal pili, although supporting cellular adherence, do not promote epithelial invasion.

\section{Results}

\section{The invasive phenotype of N.gonorrhoeae is subject to phase variation}

Preliminary electron microscopical studies have suggested that piliated N.gonorrhoeae MS11-F3, a well characterized laboratory strain, is essentially non-invasive for Chang conjunctiva cells while a recent clinical isolate, VP1, is highly invasive. Since piliated $N$. gonorrhoeae are naturally competent for DNA uptake via transformation (Sparling, 1966), our initial intention was to complement the lack of invasiveness of strain MS11 by transformation with purified DNA from the invasive strain VP1; this would allow us to identify genetic determinants essential for the invasive phenotype of N.gonorrhoeae. To pursue this, we chose to select for intracellular gonococci by use of the antibiotic gentamicin $(\mathrm{Gm})$, which preferentially kills extracellular bacteria (Isberg and Falkow, 1985).

Unexpectedly, we observed that, regardless of whether or not transforming DNA from the invasive strain was present, we were able to isolate small numbers of recipient bacteria showing invasive properties. Individual clones of MS11-F3 recovered from the $\mathrm{Gm}$ invasion assay showed a $10^{2}$ - to $10^{3}$-fold increase in survival rate when subjected to a subsequent $\mathrm{Gm}$ assay (Figure 1A, compare parent $\mathrm{F} 3$ and subclone F3.1). Hence the ability to enter epithelial cells appeared to be an intrinsic trait of $N$. gonorrhoeae that could be turned on at moderate rates and was then inherited.

The number of intracellular bacteria surviving $\mathrm{Gm}$ treatment increased over several hours (Figure 1A) and, under the conditions used, the inoculated gonococci multiplied $\sim 10$-fold during the first $6 \mathrm{~h}$ of incubation (data not shown). In accordance with previous reports (Bessen and Gotschlich, 1986) the internalization of MS11 gonococci by Chang epithelial cells was abrogated in the presence of 2.5 $\mu \mathrm{g} / \mathrm{ml}$ cytochalasin $\mathrm{D}$, suggesting an active involvement of the epithelial target cells in the invasion process (Figure 1B). Although the recovery of bacteria from the $\mathrm{Gm}$ assay does not formally prove the intracellular location of the bacteria, this notion is confirmed by microscopy studies presented below.

\section{Epithelial invasion correlates with the production of distinct Opa proteins}

Several subclones of MS11-F3 obtained after one intracellular passage through Chang cells were analysed with regard to their outer membrane protein composition. Polyacrylamide gel analysis demonstrated that clones showing an increased invasiveness had the same outer membrane and LPS patterns except for an extra protein of $30 \mathrm{kd}$ compared with the original variant. Interestingly, this protein $\left(\mathrm{Opa}_{30}\right)$ could be identified by immunoblotting as a member of the Opa protein family (Figure 2A; Stern et al., 1984). A few other clones recovered had no Opa protein or an Opa protein of different size; these clones, however, showed no increased recovery rates in a subsequent $\mathrm{Gm}$ assay and probably resulted from incomplete killing of extracellular adherent bacteria by Gm (van Putten, 1991).

Since some of the intracellularly passaged MS11-F3 subclones (including F3.1 and F3.2) had lost the expression of pili, we repeated the same experiment with strain MS11-B2, a non-piliated mutant deleted in both pilin expression loci of strain MS11 (Segal et al., 1985). Using the B2 mutant, the above described results were reproduced; the original MS11-B2 only showed marginal invasion and, of the few subclones recovered from intracellular passage, about $90 \%$ were highly invasive in a second passage, pro-
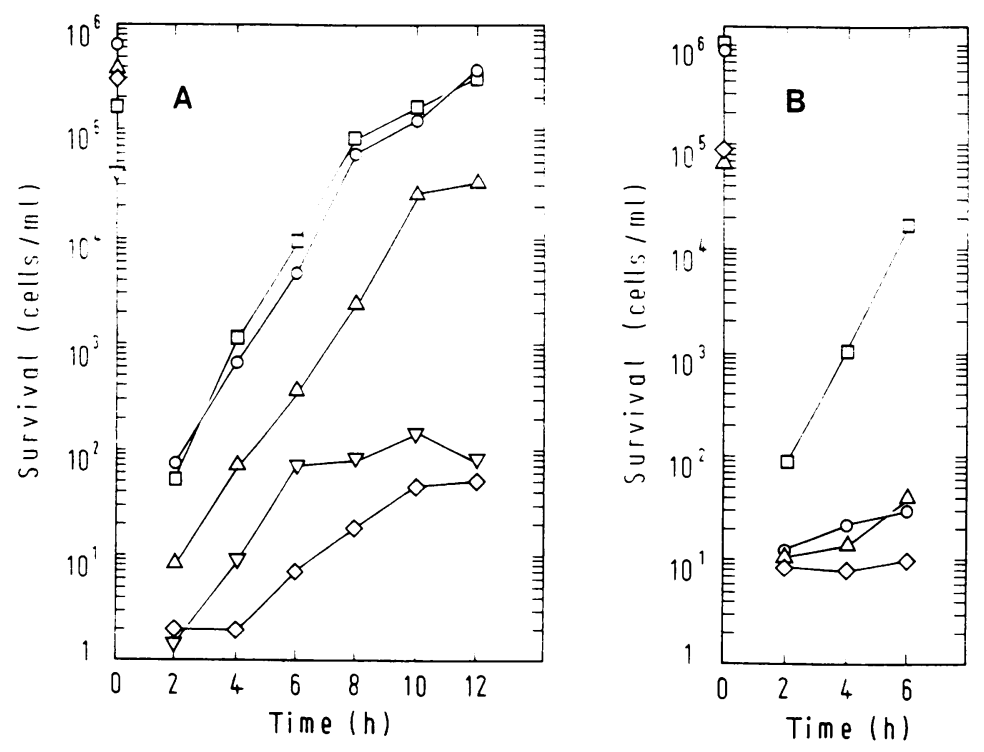

Fig. 1. Kinetics of epithelial cell invasion by N.gonorrhoeae MS11 variants and inhibition of invasion by cytochalasin D. (A) The graphs show the number of Chang cell internalized gonococci recovered after $\mathrm{Gm}$ exposure. The infection times refer to the times of $\mathrm{Gm}$ addition. The zero time point indicates the number of total Chang cell associated (adherent) gonococci at $2 \mathrm{~h}$ after infection: $\diamond, \mathrm{F}^{3}\left(\mathrm{P}^{+}, \mathrm{Opa}^{-}\right)$; $O$, variant $\mathrm{F} 3.1$ (L, $\left.\mathrm{Opa}_{30}\right) ; \triangle$, variant F3.3 $\left(\mathrm{P}^{+}, \mathrm{Opa}_{30}\right) ; \nabla, \mathrm{B} 2\left(\mathrm{P}_{\mathrm{n}}, \mathrm{Opa}^{-}\right) ; \square$, variant B2.1 $\left(\mathrm{P}_{\mathrm{n}}, \mathrm{Opa}_{30}\right)$. (B) Variants of MS11 were tested accordingly in the presence or absence of cytochalasin D: $\bigcirc$, variant F3.1 (L, Opa 30$)$ with, and $\square$, without cytochalasin $\mathrm{D} ; \diamond, \mathrm{B} 2\left(\mathrm{P}_{\mathrm{n}}, \mathrm{Opa}^{-}\right)$with, and $\triangle$, without cytochalasin D. 
ducing an Opa protein identical in size with the Opa produced by the invasive MS11-F3 subclones (compare variants B2 and B2.1 in Figures $1 \mathrm{~A}$ and $2 \mathrm{~A}$ ).

The strain $N$.gonorrhoeae VP1, expresses a different repertoire of Opa proteins compared with strain MS11. The original invasive variant produced five Opa proteins simultaneously, ranging in size from 27 to $30 \mathrm{kd}$ (Figure 2B). To test if one or several particular Opa proteins were responsible for the invasive properties of this strain, spontaneous variants of VP1 were derived by visual monitoring of the colony opacity. A number of variants obtained in this fashion had lost the expression of one, several or all Opa proteins (Figure 2B) and also revealed substantial differences with regard to their invasiveness (Figure 3). After $6 \mathrm{~h}$ of incubation with Chang cells the highest levels of intracellular bacteria were noted for the original VP1 strain, variant VP1.7 producing a $27.5 \mathrm{kd}$ Opa protein and variant VP1.8 producing the $27.5 \mathrm{kd}, 29 \mathrm{kd}$ and $30 \mathrm{kd}$ Opa proteins
(Figures 2B and 3). Thus, expression of a $27.5 \mathrm{kd} \mathrm{Opa}$ protein (here referred to as $\mathrm{Opa}_{27.5}$ ), which is absent in the non-invasive variants, correlates with epithelial cell invasion by strain VP1. A non-invasive Neisseria mucosa strain devoid of opa determinants served as a control in all invasion experiments.

\section{Microscopical confirmation of gonococcal internalization}

To correlate the survival rates of gonococci determined in the $\mathrm{Gm}$ assay with the gonococcal internalization by Chang conjunctiva cells, both immunofluorescence microscopy and electron microscopy of thin sections were applied. The immunofluorescence experiment presented in Figure 4 shows internalized bacteria at different time points after inoculation. Two hours after inoculation with variant B2.1 $\left(\mathrm{Opa}_{30}{ }^{+}\right)$, gonococci can already be seen intracellularly and their number rapidly increases during the $24 \mathrm{~h}$ incubation period.

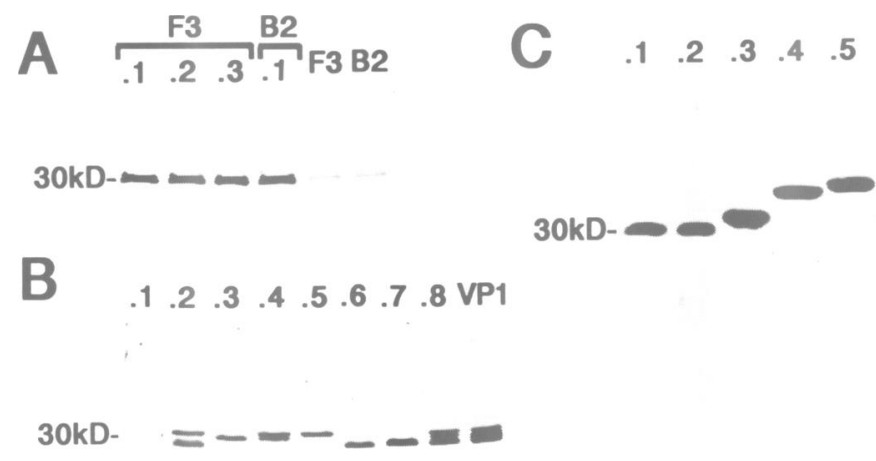

Fig. 2. Opa protein expression of gonococcal variants derived from strains MS11 and VP1. Immunoblots showing Opa proteins in boiled total cell lysates of (A) MS11-F3 and MS11-B2, and their invasive derivatives F3.1 to F3.3 and B2.1, (B) Opa variants of strains VP1, i.e. variant VP1.1 (no Opa protein), VP1.2 (27 kd, $30 \mathrm{kd})$, VP1.3 (29 kd), VP1.4 (29 kd, $30 \mathrm{kd})$, VP1.5 (30 kd), VP1.6 (27 kd), VP1.7 (27.5 kd), VP1.8 (27.5 kd, 29 $\mathrm{kd}, 30 \mathrm{kd})$, VP1 $(27 \mathrm{kd}, 27.5 \mathrm{kd}, 28 \mathrm{kd}, 29 \mathrm{kd}, 30 \mathrm{kd})$, and (C) invasive variant B2.1 and other derivatives of MS11-B2 selected for increased adherence to Chang cells (B2.2 to B2.5). It should be noted that the coincidence in size of some MS11 and VP1 Opas does not imply any structural or functional relatedness.

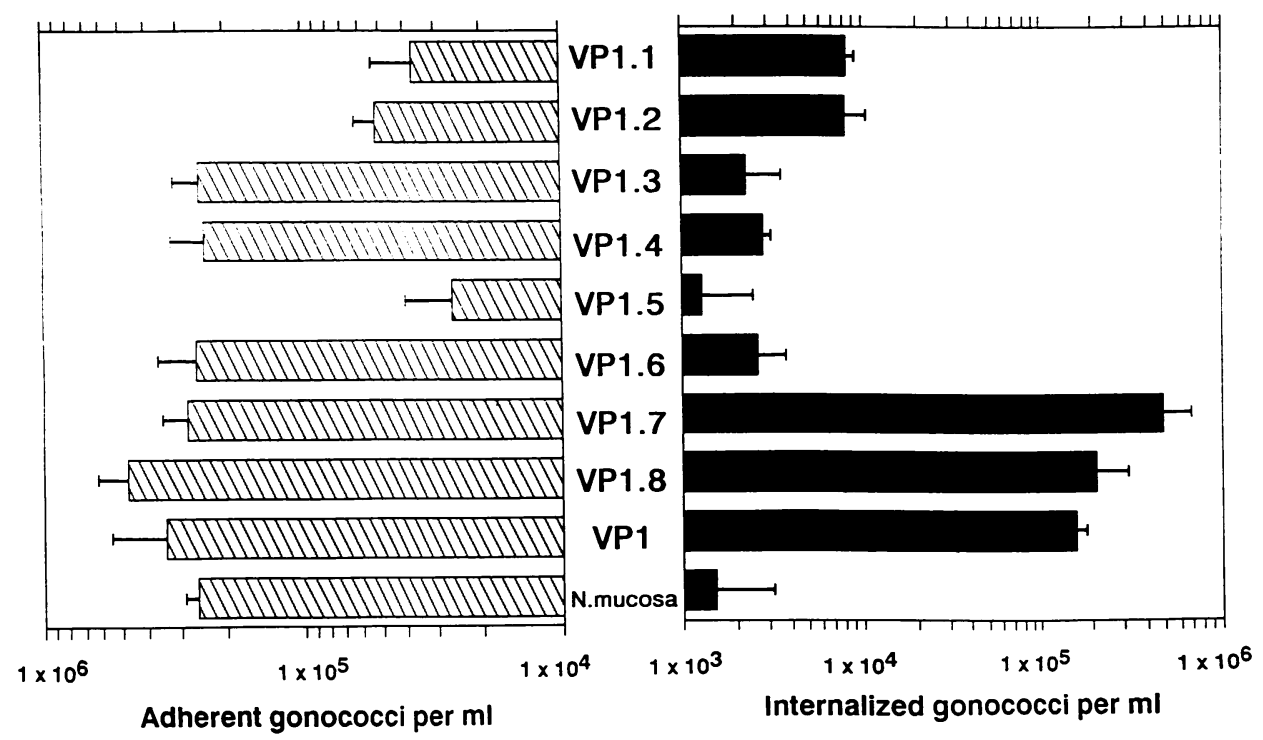

Fig. 3. Chang cell specific adhesion and invasion of isogenic N.gonorrhoeae VP1 Opa variants. The numbers of adherent (hatched) and Gm resistant internalized (black) gonococci are indicated as the average of three independent experiments according to the protocol outlined in Figure 1, with internalized gonococci measured after a $6 \mathrm{~h}$ incubation. The expression of Opa proteins by the individual VP1 variants is shown in Figure $2 \mathrm{~B}$. The adherent but non-invasive $N$. mucosa strain was included as a standard. 

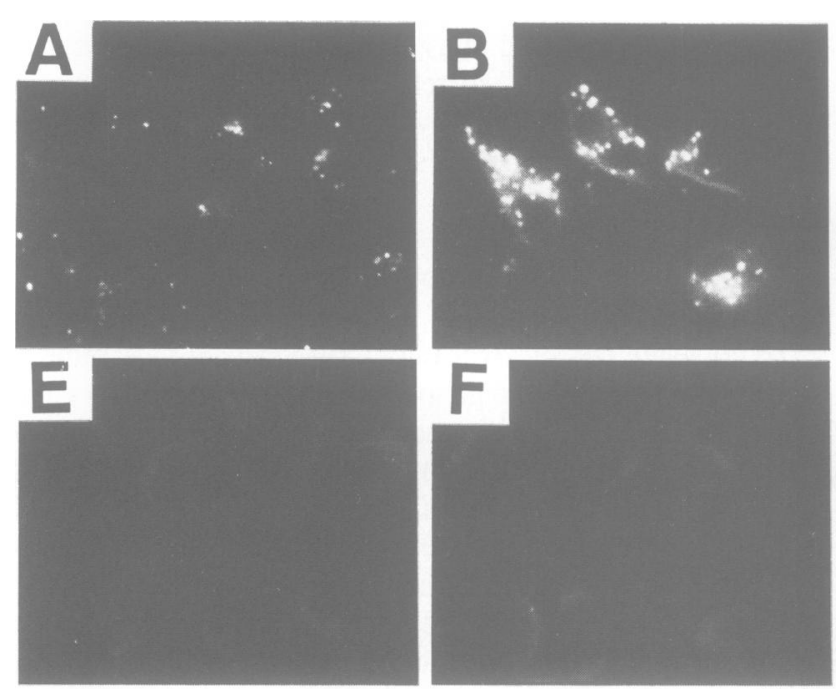
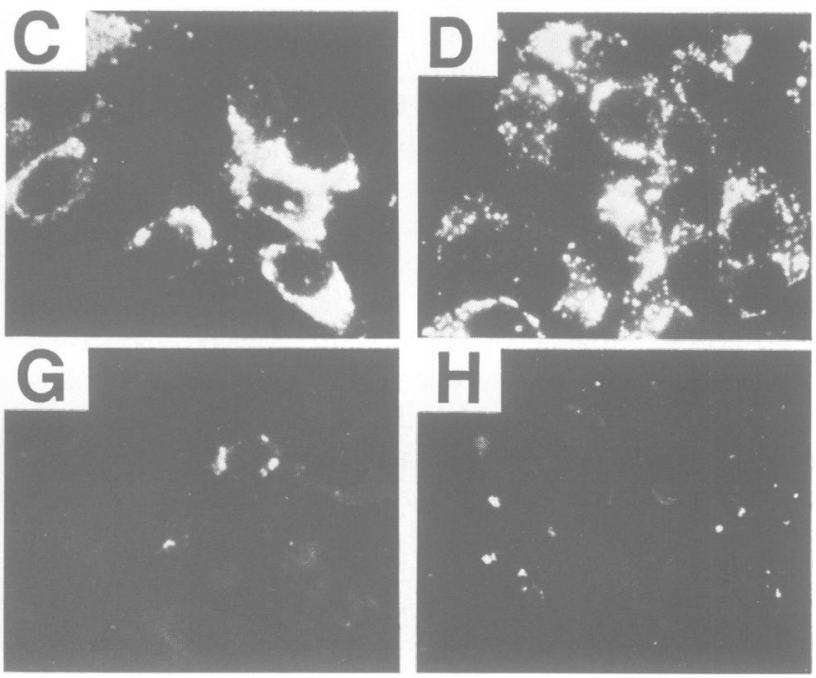

Fig. 4. Immunofluorescence micrographs showing the internalization of $\mathrm{Opa}_{30}{ }^{+}$and $\mathrm{Opa}^{-} \mathrm{MS} 11-\mathrm{B} 2$ gonococci by Chang epithelial cells. Panels A-D, variant B2.1 $\left(\mathrm{Opa}_{30}{ }^{+}\right) 2 \mathrm{~h}, 6 \mathrm{~h}, 10 \mathrm{~h}$ and $24 \mathrm{~h}$ after infection, and panels $\mathbf{E}-\mathbf{H}$, variant B2 (Opa $\left.{ }^{-}\right) 2 \mathrm{~h}, 6 \mathrm{~h}, 10 \mathrm{~h}$ and $24 \mathrm{~h}$ after infection of Chang cells. The non-adherent bacteria were carefully removed from the Chang cells by washing $2 \mathrm{~h}$ after infection before the standard infection protocol was continued. This was necessary to minimize the number of extracellular adherent bacteria in microscopy. The intracellular and remainder extracellular gonococci were visualized by immunofluorescence using a rabbit antiserum raised against whole gonococci, and protein A-TRITC. Controls showed that the number of extracellular adherent gonococci was negligible after the Gm treatment.
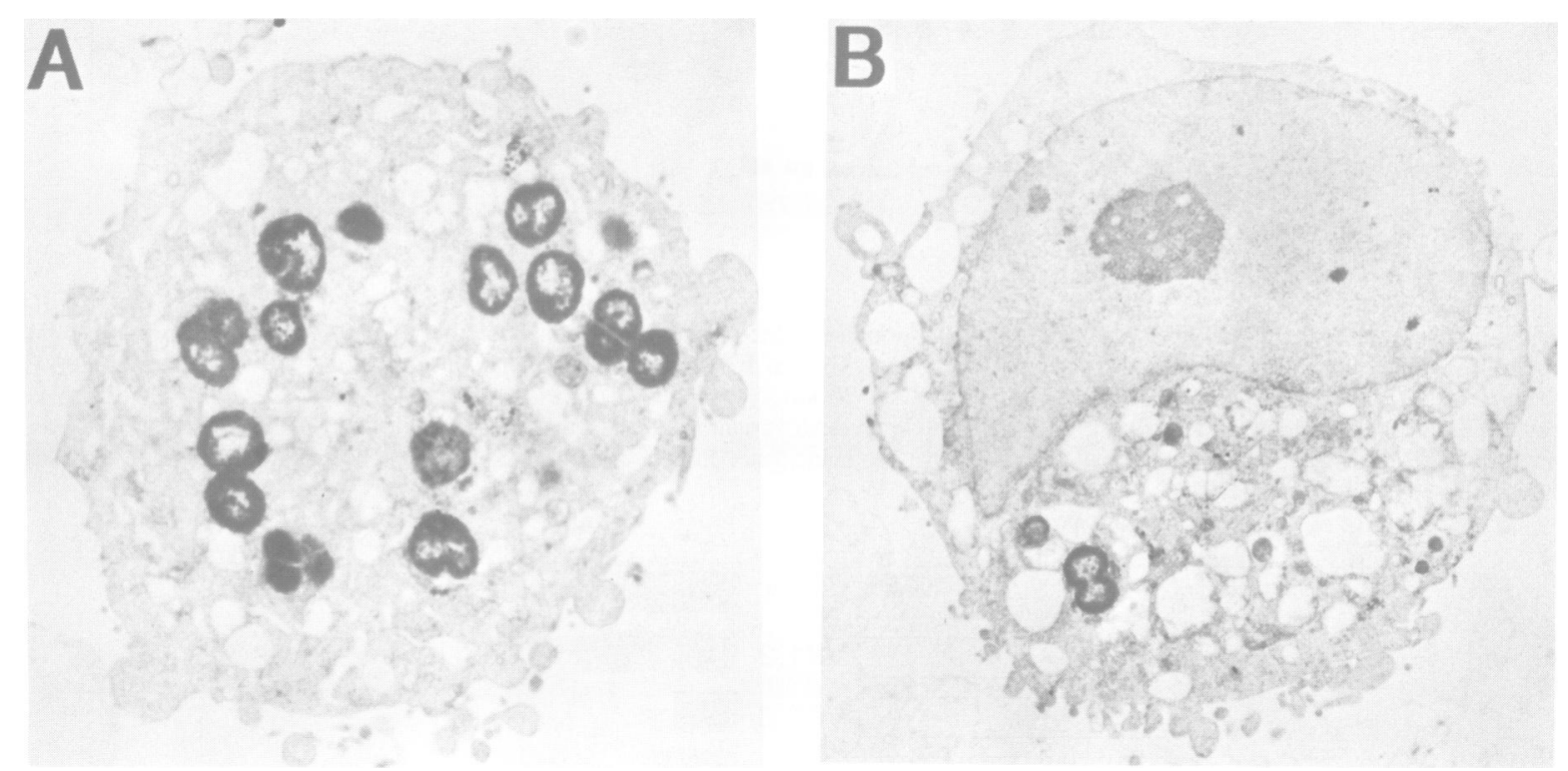

Fig. 5. Electron microscopy of thin sections of infected Chang cells. The sections shown are representative of Chang conjunctiva cells infected by (A) the MS11 variant B2.1 $\left(\mathrm{Opa}_{30}\right)$ and $(\mathbf{B})$ variant B2.3 $\left(\mathrm{Opa}_{31}\right)$. The Chang cells were infected $8 \mathrm{~h}$ prior to $\mathrm{Gm}$ treatment.

On average, a single Chang cell contained about 24 internalized gonococci at $10 \mathrm{~h}$ after inoculation with variant B2.1 $\left(\mathrm{Opa}_{30}{ }^{+}\right), 100$ times more than in the control experiment with parental B2 $\left(\mathrm{Opa}^{-}\right)$gonococci. Again, when the few internalized bacteria obtained from aliquots of the latter experiment were grown up and tested by immunoblotting, the majority was found to produce $\mathrm{Opa}_{30}$, suggesting that the residual degree of invasion is also due to $\mathrm{Opa}_{30}{ }^{+}$gonococci. These variants probably either existed in the original inoculum at the time of infection or may have switched to the $\mathrm{Opa}_{30}$ phenotype during incubation. In electron microscopy of thin sections, variant B2.1 $\left(\mathrm{Opa}_{30}{ }^{+}\right)$ gives rise to an average of 6 gonococci per sectioned cell
(Figure 5A), while the control strain B2 $\left(\mathrm{Opa}^{-}\right)$shows $<0.1$ intracellular bacteria per sectioned cell (data not shown).

Both microscopic techniques confirm the role of $\mathrm{Opa}_{30}$ in gonococcal invasion of Chang cells. The comparison of the microscopical and the $\mathrm{Gm}$ assay data, however, reveals drastic differences, in that the number of MS11 gonococci recovered from the $\mathrm{Gm}$ assay is about 100 times lower than expected from the microscopical data (compare with Figure 1A). This may indicate that the majority of gonococci are killed within epithelial cells, as is reported for professional phagocytes (Parsons et al., 1986), and that only a small percentage of gonococci can survive the intra-epithelial stage. 


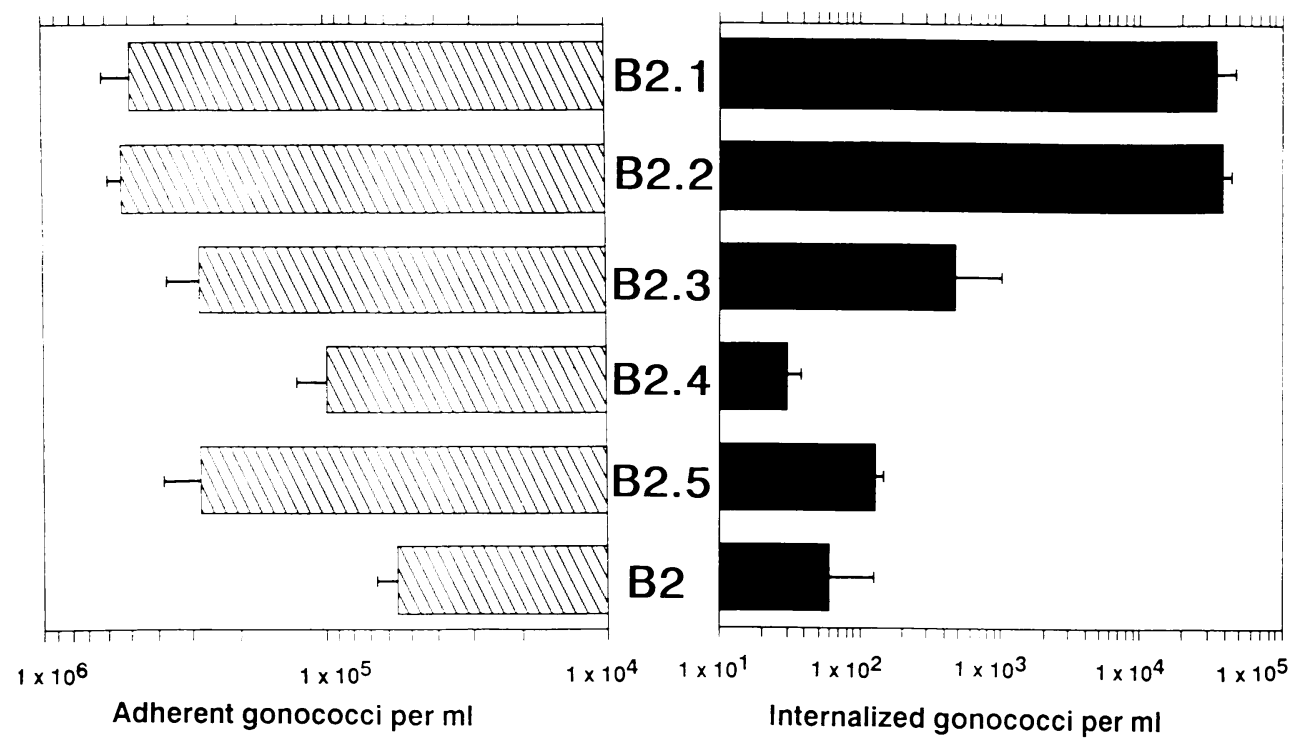

Fig. 6. Invasiveness of MS11-B2 variants selected for increased adherence to Chang conjunctiva cells. The numbers of adherent and internalized gonococci were obtained in three independent experiments using the protocol of Figure 3. Variants B2.2. B2.3. B2.4 and B2.5 were isolated based on their increased adherence to Chang conjunctiva cells. The Opa protein profile of these variants is shown in Figure 2C. For comparison the MS11-B2 parent strain and its derivative B2.1. which was selected for increased invasiveness but otherwise identical to variant B2.2. have been included in this experiment.

The limited survival of internalized gonococci is also suggested by the approaching plateau in the number of recoverable $\mathrm{Gm}$ resistant bacterial counts after $6-8 \mathrm{~h}$ of incubation with Chang cells (Figure 1). In contrast, the Chang conjunctiva cells remain viable even under a heavy burden of internalized gonococci and further multiply if extracellular gonococci are killed by continued exposure to Gm (data not shown).

\section{Opa proteins as adherence mediators}

The increased invasiveness of Opa variants appeared to be associated with an increased extracellular adherence of the gonococci to the target cells, although these differences did not exceed a factor of 10 (Figures $1 \mathrm{~A}$ and 3). To investigate whether strong Opa-mediated adherence was a sufficient prerequisite for epithelial invasion. we selected variants of MS11-B2 for increased adherence in order to test their invasiveness subsequently. Non-piliated MS11-B2 gonococci were incubated with Chang cells for $2 \mathrm{~h}$, then unbound bacteria were carefully removed by repeated washings and the adherent bacteria plated out. Four different types of variants, B2.2, B2.3, B2.4 and B2.5 producing Opa proteins between 30 and $33 \mathrm{kd}$, respectively, could be identified (Figure 2C). In separate assays. an increased adherence was confirmed for three of these variants (Figure 6). In the Gm invasion assay variants $\mathrm{B} 2.1$ and $\mathrm{B} 2.2$ producing $\mathrm{Opa}_{30}$ gave the highest values and another variant. B2.3. producing an $\mathrm{Opa}_{31}$ protein, was second. with a value $\sim 100$-fold lower (Figure 6). This difference corresponded to electron microscopy thin sectioning data. revealing at least 8 times fewer intracellular B2.3 gonococci in comparison with variant B2.1 (Figure 5A and B). The greater difference in the invasiveness of the two variants revealed in the Gm assay compared with the electron microscopy experiment may reflect differences in the ability of gonococcal variants to survive intracellularly. This may also hold true for strain VP1, which gave up to 10-fold higher yields of viable intracellular bacteria compared with invasive variants of
Table I. Invasiveness of MS11 piliation variants

\begin{tabular}{lllll}
\hline Variant $^{\mathrm{d}}$ & Parent & Opa $_{30}$ & Piliation $^{\mathrm{b}}$ & Invasion $^{\mathrm{c}}$ \\
\hline B2 & MS11 & - & $\mathrm{P}_{\mathrm{n}}$ & - \\
B2.1 & B2 & + & $\mathrm{P}_{\mathrm{n}}$ & ++ \\
B2.1.1 & B2.1 & - & $\mathrm{P}_{\mathrm{n}}$ & - \\
F3 & MS11 & - & $\mathrm{P}^{+}$ & - \\
F3.1 & F3 & + & $\mathrm{L}$ & ++ \\
F3.1.2 & F3.1 & - & $\mathrm{L}$ & - \\
F3.1.3 & F3.1 & + & $\mathrm{P}^{+}$ & + \\
F3.3 & F3 & + & $\mathrm{P}^{+}$ & + \\
F3.3.2 & F3.3 & + & $\mathrm{L}$ & ++ \\
F3.3.1 & F3.3 & + & $\mathrm{P}_{\mathrm{n}}$ & ++ \\
\hline
\end{tabular}

"Variants were derived from their parent strains as specified in Materials and methods. The expression of Opas and pilin was confirmed by immunoblotting of aliquots of the inocula, as appropriate.

${ }^{h}$ Nomenclature of piliation status is according to Gibbs et al. (1989). 'The efficiency of Chang conjunctiva cell invasion refers to the levels measured for B2.1 $(++)$ invasive. F3.3 (+) weakly invasive. and B2 $(-)$ non-invasive. in correspondence to the experiment presented in Figure $1 \mathrm{~A}$

"See Segal et al. (1985)

'See Haas et al. (1987).

strain MS11. In toto the data indicate that strong adherence is necessary but probably not sufficient for invasion (Figure $3)$.

\section{Role of pili in the invasion of Chang cells}

Our initial findings with the non-piliated MS11-B2 mutant implied that pili, and hence pilus mediated adherence, are not necessary for the invasion of epithelial cells under in vitro conditions. Subsequent analysis of strain VP1 also showed that the invasive variant used does not produce typical pilin and appears bald in the electron microscope (data not shown). Moreover, the observation that MS11-F3 variants recovered from an intracellular passage had often lost the ability to form normal pili suggests that piliation may 

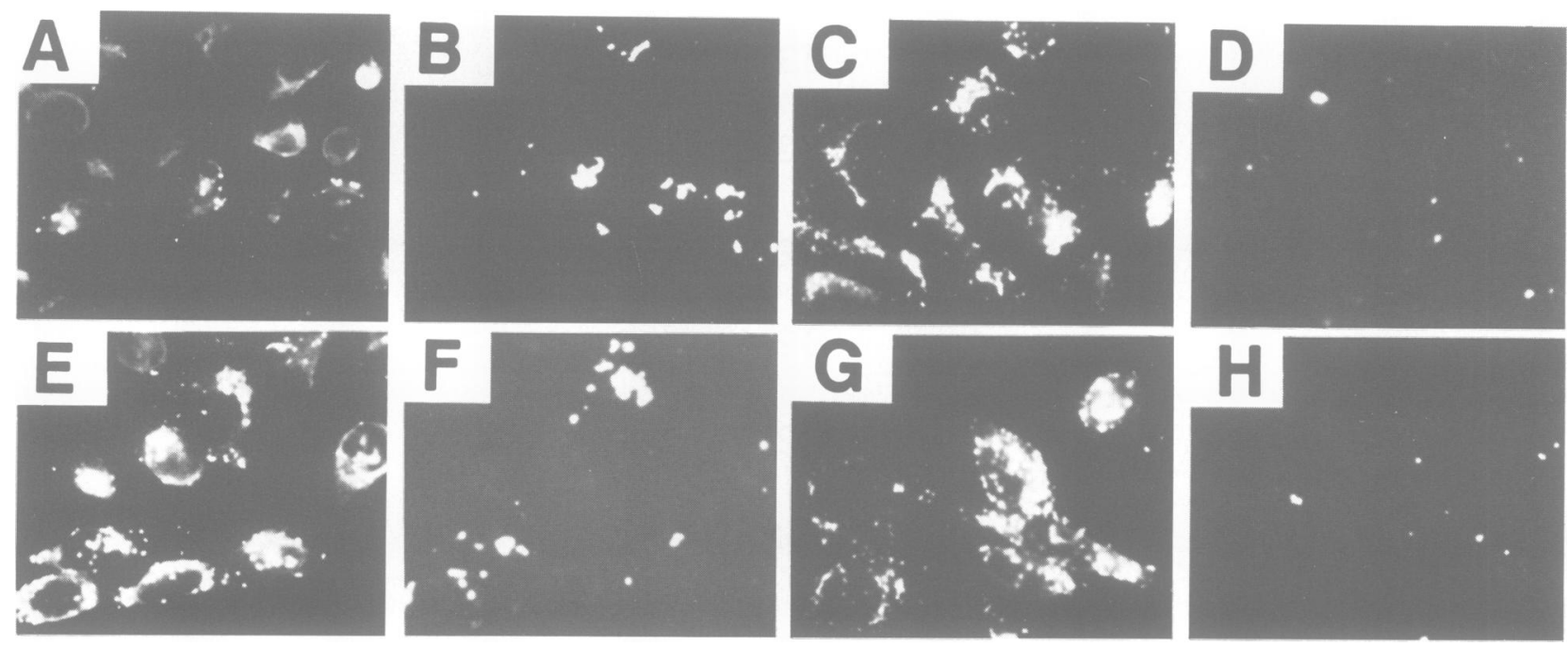

Fig. 7. Invasiveness of piliated and non-piliated $\mathrm{Opa}_{30}{ }^{+}$variants. Chang cells were inoculated with MS11 variants $\mathrm{F} 3.3\left(\mathrm{P}^{+}, \mathrm{Opa} 30\right)(\mathbf{A}-\mathbf{D})$ and F3.1 ( L, Opa $\left.{ }_{30}\right)(\mathbf{E}-\mathbf{H})$ and non-adherent bacteria were removed $2 \mathrm{~h}$ after infection. The infected Chang cells were then further incubated for $4 \mathrm{~h}$ $(\mathrm{A}, \mathrm{B}, \mathrm{E}$ and $\mathrm{F})$ or $22 \mathrm{~h}(\mathrm{C}, \mathrm{D}, \mathrm{G}$ and $\mathrm{H})$. Double fluorescence labelling was performed in order to discriminate extracellular (B, D, F, and H) from intracellular (A, C, E, and G) gonococci, as described in Materials and methods.

be unfavourable for epithelial invasion. We therefore investigated in detail the influence of piliation on invasion by MS11 variants (Table I). Three different piliation types, non-piliated $P_{n}$ deletion mutants, which do not produce pilin (Bergström et al., 1986), non-piliated L variants, which produce an abnormal pilin (Haas et al., 1987; Manning et al., 1991), and piliated variants were tested in $\mathrm{Opa}_{30}$, positive and negative backgrounds. In the absence of $\mathrm{Opa}_{30}$, all pilin variants were essentially non-invasive. In the presence of $\mathrm{Opa}_{30}$ both non-piliated phenotypes showed $\sim 10$-fold greater invasion compared with the $\mathrm{P}^{+}$variant MS11-F3 (Figure 1A).

Since we previously noticed an increased resistance of nonpiliated $L$ variants and $P_{n}$ mutants of strain MS11 to kanamycin and penicillin but not chloramphenicol (Gibbs et al., 1989), we wanted to exclude the possibility that nonpiliated variants would be selected for by the use of $\mathrm{Gm}$. $L$ variants and $P_{n}$ mutants were about 4-fold more resistant to kanamycin than were $\mathrm{P}^{+}$, in accordance with our previous data, but had a similar resistance to $\mathrm{Gm}$ (data not shown).

Double label immunofluorescence experiments, which allowed microscopic discrimination between intra- and extracellular bacteria, provided further support for the increased invasiveness of non-piliated over piliated gonococci (Figure 7). Four hours after inoculation, similar numbers of extracellular bacteria were found for both $\mathrm{P}^{+}$and $\mathrm{L}$ forms of $\mathrm{Opa}_{30}{ }^{+} \mathrm{MS11}$ variants, while the numbers of intracellular organisms differed in that large numbers of $\mathrm{L}$ but only few $\mathrm{P}^{+}$organisms were internalized. This result was different after a $24 \mathrm{~h}$ incubation period, showing about equal numbers of intracellular gonococci for both variants. This discrepancy, together with the fact that non-piliated variants were often observed after intracellular passage of piliated $\mathrm{F} 3$, suggested that during the long incubation period, gonococci began to acquire a more invasive non-piliated phenotype. This notion was confirmed in that a majority of gonococci recovering from this long term incubation had lost pili formation (data not shown).
Table II. Influence of piliation on the invasiveness of $r e c \mathrm{~A}$ deficient MS11 derivatives

\begin{tabular}{|c|c|}
\hline Strain & Invasion Adh \\
\hline $\begin{array}{l}\text { F3.3R }\left(\operatorname{recs}^{-}, \mathrm{P}^{+}, \mathrm{Opa}_{30}{ }^{+}\right) \\
\text {F3.4R (rect } \\
-\end{array}$ & $\begin{array}{ll}(1.9+0.1) \times 10^{5} & (2.0+0.8) \times 10^{1} \\
(1.0+0.2) \times 10^{5} & (5.7+1.4) \times 10^{3}\end{array}$ \\
\hline
\end{tabular}

Results represent the average of three experiments. The m.o.i. of bacteria to Chang cells in the inoculum was 8.0. Adherence and invasiveness were measured as described in Materials and methods. Invasion refers to the number of antibiotic resistant gonococci that survived $120 \mathrm{~min}$ exposure to gentamicin, following bacterial infection for $10 \mathrm{~h}$.

In order to eliminate pilin phase transitions, we constructed a pair of rec $\mathrm{A}^{-} \mathrm{Opa}_{30}{ }^{+}$derivatives of MS11-F3 by allelic replacement, which were phenotypically identical except for the production of pili. These recA mutants showed no antigenic variation (Koomey et al., 1987) and a decrease in phase variation (C.P.Gibbs and T.F.Meyer, unpublished data). Both recA mutants showed similar growth rates and adhered equally well to Chang conjunctiva cells. However, the $P_{n}$ strain gave rise to 100 times more viable intracellular gonococci in the $\mathrm{Gm}$ assay than the corresponding $\mathrm{P}^{+}$strain (Table II). The overall invasion rates in this experiment were low, probably as a consequence of significantly slower growth of rec $\mathrm{A}^{-}$gonococci compared with the wildtype organisms.

\section{Discussion}

This work demonstrates a central role of Opa proteins in the penetration of human Chang conjunctiva cells by N.gonorrhoeae. Owing to phase transitions in the expression of Opa proteins, non-invasive gonococci can acquire an invasive phenotype, and vice versa. The frequency of Opa phase transitions in N.gonorrhoeae, which is of the order of $10^{-3}$ (Mayer, 1982; Stern et al., 1986; Murphy et al. 1989), explains the spontaneous generation of invasive phase variants of strain MS11 in our assay. However, only distinct Opa proteins (particularly $\mathrm{Opa}_{30}$ for strain MS11 and 
$\mathrm{Opa}_{27.5}$ for strain VP1) were competent in conferring a high degree of invasiveness on the gonococcus with regard to the Chang cell line. It awaits further analysis to see whether a structural basis exists for the functional similarity of the two Opa alleles. Other members of the Opa protein families of these strains either conferred low levels of invasiveness or had no influence on the interaction between the bacteria and the Chang cells. In general it appeared that efficient adherence of gonococci to epithelial cells due to Opa was a prerequisite for the invasion of the epithelial cells.

Previous investigations were concerned with the adherence functions of Opa proteins which play a role in the interaction with both human epithelial and phagocytic cells (Lambden et al., 1979; Virji and Everson, 1981; Sugasawara et al., 1983; Bessen and Gotschlich, 1986; Elkins and Rest, 1990). Several studies with human leukocytes indicated a substantial degree of specificity in the adherence of certain Opa proteins to these cells. Likewise the expression of a member of the Opa protein family, the leukocyte association factor, allowed gonococci to adhere to human polymorphonuclear cells (King and Swanson, 1978). Virji and Heckels (1986) observed that Opa proteins were essential for the ingestion of gonococci by professional phagocytes and in another study such interactions appeared to depend on distinct Opa proteins (Fischer and Rest, 1988). The data presented here suggest preferences of distinct Opa proteins in both Chang cell adherence and invasion. Preliminary data further suggest that for strain MS11 the respective Opa protein $\left(\mathrm{Opa}_{30}\right)$ also confers invasiveness to HeLa and HecIB cells but that at least one additional Opa protein is also active in relation to PC3 cells (S.Makino, unpublished data). It is possible that individual members of the Opa protein family preferentially interact with a subset of human cells, such as epithelial and phagocytic cells, although this has not yet been clearly demonstrated for a defined strain. Opa variation in the gonococcus may therefore not only be a matter of immune evasion but additionally a means to alter or modulate the tissue tropism of this species. This two-fold implication of phase and antigenic variation was recently also suggested for the variation of gonococcal pili (Meyer and van Putten, 1989).

Although gonococcal pili confer strong adherence to Chang conjunctiva cells (Virji and Everson, 1981), we found that these organelles do not facilitate the invasion process in vitro. Similar conclusions were drawn by Shaw and Falkow (1988), who demonstrated internalization of nonpiliated gonococci in HecIB cells. In some invasion experiments described here, the majority of the bacteria isolated passaged through Chang cells were no longer piliated, suggesting a selective advantage for non-piliated gonococci. Moreover, piliated gonococci unable to undergo phase variation due to a deletion in the recA locus, were about two orders of magnitude less invasive than their nonpiliated counterparts. This brings to mind previous data suggesting that pili elicit antiphagocytic effects (Punsalang and Sawyer, 1973; Thongthai and Sawyer, 1973; Ofek et al., 1974; Densen and Mandell, 1978), although this notion has not been confirmed by others (Virji and Heckels, 1986). Whether the inhibitory effect of piliation is influenced by the particular type of pilin variant studied (i.e. MS11-F3, Haas et al., 1987) remains to be evaluated.

The data presented contrast with in vivo infection experiments (Swanson et al., 1988) and observations in organ culture models (McGee et al., 1983; Tjia et al., 1988), which both suggest an essential role of the pili during infection, probably serving as the initial anchors of gonococci in the human mucosa. However, the in vivo environment is markedly different from the in vitro cell culture system, probably with many additional physical constraints. Hence it is quite likely that pili are essential in vivo but dispensable in vitro, solely indicating that they are not directly involved in the invasion process. Even in the natural situation the nonpiliated phenotype may be the preferred phase in cellular invasion and, in order to enter an invasive stage, the adherent gonococci may have to switch to an invasion-competent (i.e. non-piliated and $\mathrm{Opa}^{+}$) phenotype. It is noteworthy in this regard that loss of pili formation can be achieved not only by phase variation but also by environmental regulation (Taha et al., 1988).

Since our data appear to suggest the killing of a majority of gonococci after internalization by Chang conjunctiva cells, the role of pili may also be interpreted as being protective. This view would be in agreement with the importance of pili for the gonococcal survival in vivo, e.g., in implantation chambers (Veale et al., 1974). It raises, however, questions about the significance of the intracellular phase of gonococci and thus about the role of invasion promoting Opa proteins in the infection process. To resolve this dilemma, detailed studies on the mechanism by which pili inhibit or perhaps alter the invasion process may be pertinent.

The mechanisms by which Opa proteins stimulate the invasion process are not yet understood. Possibly Opa proteins act in a way similar to the invasin of Yersinia pseudotuberculosis which not only confers invasion but also adherence. While it was shown that the Yersinia invasin induces the phagocytic process in epithelial cells even when expressed in E.coli (Isberg et al., 1987), a cloned constitutively expressed Opa of N.gonorrhoeae strain F62 did not confer invasiveness on E.coli (Palmer et al., 1989); this does not necessarily contradict the above notion, though, because the respective F62 Opa protein was not shown to confer invasiveness on the parental gonococcal strain. Besides, other gonococcal factors may contribute to the process of epithelial invasion by $N$.gonorrhoeae as suggested by the 10-fold higher invasion level of strain VP1 in comparison with the invasive variants of strain MS11. A multifactorial basis of the invasion process has also been assumed for pathogens, such as Salmonella spp. (Elsinghorst et al., 1989; Galán and Curtiss, 1989) and Shigella flexneri (Makino et al., 1986; Sansonetti et al., 1986).

It has been suggested that the Opa protein adhesins recognize carbohydrate structures on the surface of human cells (Rest $e t$ al., 1985), and that some members of the Opa protein family confer inter-gonococcal adherence probably involving the carbohydrate moieties of gonococcal lipopolysaccharide (LPS) as a receptor (Blake, 1985). The identification of the putative receptor(s) for Opa on epithelial cells is likely to shed new light on the gonococcal invasion process. Likewise the receptor for the Y. pseudotuberculosis invasin has been characterized as an integrin and provided an interesting clue regarding the mechanism of bacterial invasion (Leong et al., 1990). The binding of bacteria to integrins, which connect the surface of a eukaryotic cell with its (actin) microfilament network, is likely to trigger microfilament-dependent engulfment of the bound bacteria directly. As shown here and by others (Bessen and 
Gotschlich, 1986), gonococcal invasion also depends on actin polymerization. To examine how Opa proteins stimulate the engulfment of gonococci by epithelial cells will be a future research goal.

\section{Materials and methods}

\section{Bacterial strains}

N.gonorrhoeae MS11-F3 ( $\mathrm{P}^{+}, \mathrm{Opa}^{-}$; Haas et al., 1987), MS11-B2 ( $\mathrm{P}_{\mathrm{n}}$, $\mathrm{Opa}^{-}$; Segal et al., 1985), the recent isolate N.gonorrhoeae VP1 (strain 830563; $\mathrm{P}_{\mathrm{n}}, \mathrm{Opa}^{4+}$ ) and $N . m u c o s a$ have been described previously (van Putten et al., 1990). The bacteria were grown on GC agar, and passaged daily at $37^{\circ} \mathrm{C}$ and $5 \% \mathrm{CO}_{2}$. In order to avoid contamination with undesirable Opa and/or pilin variants, N.gonorrhoeae strains were carefully monitored under a Zeiss binocular microscope upon passage. Stock cultures were prepared from single colonies and stored at $-70^{\circ} \mathrm{C}$ in PPM medium containing $5 \mathrm{mM} \mathrm{MgCl} 2,20 \%$ glycerol and $40 \mu \mathrm{g} / \mathrm{ml}$ DNase I.

\section{Isolation of phase variants and mutants of strains MS11 and \\ VP1}

To isolate invasive MS11 variants, $\sim 10^{7}$ bacteria were added to confluent Chang monolayers in a $90 \mathrm{~mm}$ Petri dish. At $2 \mathrm{~h}$ after infection, the monolayers were washed 10 times with PBS and fresh RPMI medium containing $\mathrm{Gm}(100 \mu \mathrm{g} / \mathrm{ml})$ was added, and incubation continued for 120 min at $37^{\circ} \mathrm{C}$ in $5 \% \mathrm{CO}_{2}$. After washing with PBS, the monolayers were lysed with $5 \mathrm{ml}$ of saponin solution and $100 \mu \mathrm{l}$ of the suspension was plated on GC agar plates. Bacterial colonies were randomly picked and tested for the ability to invade into Chang cells. The protein pattern was also examined by immunoblotting, as described below. In this way variants $\mathrm{B} 2.1\left(\mathrm{Opa}_{30}\right)$, F3.1 $\left(\mathrm{L}, \mathrm{Opa}_{30}\right)$ and F3.2 $\left(\mathrm{P}_{\mathrm{n}}, \mathrm{Opa}_{30}\right)$ were obtained from MS11-B2 and MS11-F3, respectively.

The spontaneous variant F3.3 $\left(\mathrm{P}^{+}, \mathrm{Opa}_{30}\right)$ was isolated from MS11-F3 $\left(\mathrm{P}^{+}, \mathrm{Opa}^{-}\right)$by screening for the expected colony opacity on $\mathrm{GC}$ agar. This variant which was not selected for in the presence of epithelial cells served as a control in invasion experiments. Non-piliated variants $\left(L\right.$ or $\left.P_{n}\right)$ and piliated revertants of $L$ variants (Manning et al., 1991) were isolated based on their characteristic colony morphologies. Spontaneous Opa variants of strain VP1 were also obtained by screening for colony opacity changes on GC agar plates.

The pair of MS11 recA mutants was constructed by allelic gene replacement by use of plasmid pC68a, containing the gonococcal recA gene with its entire coding region deleted and replaced by a chloramphenicol acetyltransferase gene (C.P.Gibbs and T.F.Meyer, unpublished), and plasmid pNG1732, containing the deleted pilE1 locus of MS11-B2 (Segal et al., 1985). The piliated recA mutant $\mathrm{F} 3.3 \mathrm{R}\left(\mathrm{rec} \mathrm{A}, \mathrm{P}^{+}, \mathrm{Opa}_{30}\right.$ ) was obtained by transforming variant $\mathrm{F} 3.3\left(\mathrm{P}^{+}, \mathrm{Opa}_{30}\right)$ with pC68a and subsequent selection on chloramphenicol $(12 \mu \mathrm{g} / \mathrm{ml})$. The non-piliated recA mutant F3.4R ( recA, $\left.\mathrm{P}_{\mathrm{n}}, \mathrm{Opa}_{30}\right)$ was constructed by co-transforming F3.3 $\left(\mathrm{P}^{+}\right.$, $\mathrm{Opa}_{30}$ ) with plasmids pC68a and pNG1732, selection on chloramphenicol and subsequent screening of the resistant clones for $P_{n}$ colony morphology. The transformation protocol has been described (Gibbs et al., 1989).

The phenotypic expression of Opa proteins and of pilin was confirmed for all variants by immunoblotting. In addition, the hybridization patterns of the pilE loci and of the chromosomal recA locus in recA mutants were confirmed by Southern blotting. The piliation status of strain MS11 is indicated by the following symbols, in accordance with Gibbs et al. (1990): $\mathrm{P}^{+}$(piliated), $\mathrm{L}$ (non-piliated due to production of extralong pilin), and $\mathrm{P}_{\mathrm{n}}$ (non-piliated and lack of pilin production due to deletions in the pilE loci).

\section{Invasion and adherence assays}

Chang conjunctiva epithelial cells, used for all adhesion and invasion assays, were maintained in RPMI 1640 medium (GIBCO) supplemented with 5\% fetal calf serum. For the infection experiments the cells were seeded into 24-well microtitre plates (Nunc) at $2 \times 10^{5}$ cells per well and incubated at $37^{\circ} \mathrm{C}$ in $5 \% \mathrm{CO}_{2}$. In the standard experiments the confluent monolayers obtained after $24 \mathrm{~h}$ were infected by $\sim 5 \times 10^{5}$ bacterial colony forming units (c.f.u.) and further incubated at $37^{\circ} \mathrm{C}$ in $5 \% \mathrm{CO}_{2}$ for various times. Thereafter the cells were washed 5 times with phosphate buffered saline (PBS) to remove non-adherent bacteria. Fresh culture medium containing $100 \mu \mathrm{g} / \mathrm{ml} \mathrm{Gm}$ was added to the wells, and the plates were further incubated at $37^{\circ} \mathrm{C}$ and $5 \% \mathrm{CO}_{2}$ for $2 \mathrm{~h}$ to kill extracellular gonococci. The medium was then removed and the infected cells were washed 3 times with PBS. In some experiments, $2.5 \mu \mathrm{g} / \mathrm{ml}$ cytochalasin D (Sigma) was added $30 \mathrm{~min}$ before the addition of bacteria. To determine intracellular and cell associated bacteria one of the following procedures was applied:
Saponin lysis. Since gonococci are relatively resistant to saponin (unpublished observations), $1 \mathrm{ml}$ of a $1 \%$ saponin solution in PBS was added to the infected Chang cells for $5 \mathrm{~min}$ at $37^{\circ} \mathrm{C}$ for lysis and to release the adherent and/or internalized bacteria. Appropriate dilutions were plated on GC agar to determine viable bacteria. To measure adherent (i.e. total Chang cell associated) bacteria the cells were also lysed with saponin, without any prior $\mathrm{Gm}$ treatment.

Immunofluorescence staining. To stain extracellular bacteria, the monolayers were first washed with PBS, and then incubated with polyclonal rabbit antiserum, raised against whole gonococci (AK92), for $60 \mathrm{~min}$ at $37^{\circ} \mathrm{C}$ followed by staining with goat anti-rabbit IgG, conjugated with fluorescein isothiocyanate (FITC), for $60 \mathrm{~min}$ at $37^{\circ} \mathrm{C}$. For the detection of intracellular bacteria, the FITC stained monolayers were fixed in PBS containing $2.7 \%$ paraformaldehyde and $0.05 \%$ glutaraldehyde for $20 \mathrm{~min}$ at room temperature. The cells were then made permeable by incubating them with $0.5 \%$ Triton $\mathrm{X}-100$ in PBS for $20 \mathrm{~min}$ at room temperature, followed by incubations with antibody AK92 and then protein A conjugated with tetramethylrhodamine isothiocyanate (TRITC). Extra- and intracellular bacteria were counted using a Nikon fluorescence microscope.

Electron microscopy. Infected epithelial cells were trypsinized to remove adherent bacteria, and fixed with $6.5 \%$ glutaraldehyde in phosphate buffer $(\mathrm{pH} 7.2)$ for $1 \mathrm{~h}$. The specimen was then treated with osmium tetroxide (2\%), dehydrated in graded ethanol and embedded in Araldite. Ultrathin sections, obtained with a glass knife, were mounted on 200 mesh formvarcoated grids and stained with uranyl acetate and lead citrate. The grids were viewed with a Zeiss EM 109 electron microscope at $80 \mathrm{kV}$.

\section{Electrophoresis and immunoblotting}

For the detection of pilin (Haas et al., 1987) and Opa proteins (Stern et al., 1984), SDS gel electrophoresis and immunoblotting were performed as described previously. All samples of cell lysates of gonococci were boiled in sample buffer at $100^{\circ} \mathrm{C}$ for $5 \mathrm{~min}$ before gel electrophoresis in order to resolve the completely denatured forms of Opa proteins.

\section{Acknowledgements}

We are grateful to Dr J.Pohlner for communicating observations regarding the invasiveness of non-piliated variants of strain MS11 in the beginning of these studies. We wish to thank Dr C.P.Gibbs for the construction of the recA deletion; B.Pichler-Brand for electron microscopic work; C.Müller for photography; and Drs P.Overath and B.D.Robertson for critical suggestions on the manuscript. S.M.gratefully acknowledges receipt of a fellowship from the Alexander von Humboldt Foundation.

\section{References}

Bergström,S., Robbins,K., Koomey,J.M. and Swanson,J. (1986) Proc. Natl. Acad. Sci. USA, 83, 3890-3894.

Bessen,D. and Gotschlich,E.C. (1986) Infect. Immun., 54, 154-160.

Blake,M.S. (1985) In Jackson,G.G. and Thomas,H. (eds), The Pathogenesis of Bacterial Infections. Springer-Verlag KG, Berlin, pp. 51-66.

Densen,P. and Mandell,G.L. (1978) J. Clin. Invest., 62, 1161-1171.

Elkins,C. and Rest,R.F. (1990) Infect. Immun., 58, 1078-1084.

Elsinghorst,E.A., Baron,L.S. and Kopecko,D.J. (1989) Proc. Natl. Acad. Sci. USA, 86, 5173-5177.

Fischer,S.H. and Rest,R.F. (1988) Infect. Immun., 56, 1574-1579.

Galán,J.E. and Curtiss,R. (1989) Proc. Natl. Acad. Sci. USA, 86, 6383-6387.

Gibbs,C.P., Reimann,B.Y., Schultz,E., Kaufmann,A., Haas,R. and Meyer,T.F. (1989) Nature, 338, 651-652.

Haas, R. and Meyer,T.F. (1986) Cell, 44, 107-115.

Haas,R., Schwarz,H. and Meyer,T.F. (1987) Proc. Natl. Acad. Sci. USA, 84, 9079-9083.

Hagblom,P., Segal,E., Billyard,E. and So,M. (1985) Nature, 315, $156-158$.

Isberg,R.R. and Falkow,S. (1985) Nature, 317, 262-264.

Isberg,R.R., Voorhis,D.L. and Falkow,S. (1987) Cell, 50, 769-778.

King,G.J. and Swanson,J. (1978) Infect. Immun., 21, 575-584.

Koomey,J.M., Gotschlich,E.C., Robbins,K., Bergström,S. and Swanson,J. (1987) Genetics, 117, 391-398.

Lambden,P.R., Heckels,J.E., James,L.T. and Watt,P.J. (1979) J. Gen. Microbiol., 114, 305-312.

Leong,J.M., Fournier,R.S. and Isberg,R.R. (1990) EMBO J., 9, 1979-1989. 
Makino,S., Sasakawa,C., Kamata,K., Kurata,T. and Yoshikawa,M. (1986) Cell, 46, 551-555.

Manning,P.A., Kaufmann,A., Roll,U., Pohlner,J., Meyer,T.F. and Haas,R. (1991) Mol. Microbiol., 5, in press.

Mayer,L.W. (1982) Infect. Immun., 37, 481-485.

McGee,Z.A., Stephens,D.S., Hoffman,L.H., Schlech,W.F. and Horn,R.G. (1983) Rev. Infect. Dis., 5, 708-S714.

Meyer,T.F. and van Putten,J.P.M. (1989) Clin. Microb. Rev., 2 , S139-145.

Meyer,T.F., Mlawer,N. and So,M. (1982) Cell, 30, 45-52.

Meyer,T.F., Billyard,E., Haas, R., Störzbach,S. and So,M. (1984) Proc. Natl. Acad. Sci. USA, 81, 6110-6114.

Meyer,T.F., Gibbs,C.P. and Haas,R. (1990) Annu. Rev. Microbiol., 44, 451-477.

Muir,L.L., Strugnell,R.A. and Davies,J.K. (1988) Infect. Immun., 56, $1743-1747$.

Murphy,G.L., Connell,T.D., Barritt,D.S., Koomey,M. and Cannon,J.G. (1989) Cell, 56, 539-547.

Nyberg,G., Strömberg,N., Jonsson,A., Karlsson,K.A. and Normark,S. (1990) Infect. Immun., 58, 2555-2563.

Ofek,I., Beachey,E.H. and Bisno,A.L. (1974) J. Infect. Dis., 129, 310-316.

Palmer,L., Brooks,G.F. and Falkow,S. (1989) Mol. Microbiol., 3, 663-671.

Parge,H.E., Bernstein,S.L., Deal,C.D., McRee,D.E., Christensen,D., Capozza,M.A., Kays,B.W., Fieser,T.M., Draper,D., So,M., Getzoff,E.D. and Tainer, J.A. (1990) J. Biol. Chem., 265, 2278-2285.

Parsons,N.J., Kwaasi,A.A., Patel,P.V., Nairn,C.A. and Smith,H. (1986) J. Gen. Microbiol., 132, 3277-3287.

Paruchuri,D.K., Seifert,H.S., Ajioka,R.S., Karlsson,K.A. and So,M. (1990) Proc. Natl. Acad. Sci. USA, 87, 333-337.

Perrollet,H. and Guinet,R.M.F. (1986) Lancet, i, 1269-1270.

Punsalang,A.P. and Sawyer,W.D. (1973) Infect. Immun., 8, 255-263.

van Putten,J.P.M. (1991) In Achtmann,M. (ed.), Proceedings of the 7th International Pathogenic Neisseria Conference. Walter de Gruyter, Berlin, in press.

van Putten,J.P.M., Hopman,C.T.P. and Weel,J.F.L. (1990) J. Med. Microbiol., 33, 35-41.

Rest,R.F., Fischer,S.H., Inghan,Z.Z. and Jones,J.F. (1982) Infect. Immun., 36, 737-744.

Rest,R.F., Lee,N. and Bowden,C. (1985) Infect. Immun., 50, 116-122.

Rest,R.F. and Shafer,W.M. (1989) Clin. Microbiol. Rev., 2, S83-S91.

Sansonetti,P.J., Ryter,A., Clerc,P., Maurelli,A.T. and Mounier,J. (1986) Infect. Immun., 51, 461-469.

Segal,E., Billyard,E., So,M., Störzbach,S. and Meyer,T.F. (1985) Cell, 40, 293-300.

Shaw,J.H. and Falkow,S. (1988) Infect. Immun., 56, 1625-1632.

Sparling,P.F. (1966) J. Bacteriol., 92, 1364-1370.

Stern,A., Nickel,P., Meyer,T.F. and So,M. (1984) Cell, 37, 447-456.

Stern,A., Brown,M., Nickel,P. and Meyer,T.F. (1986) Cell, 47, 61-71.

Strömberg,N., Deal,C., Nyberg,G., Normark,S., So,M. and Karlsson,K.A. (1988) Proc. Natl. Acad. Sci. USA, 85, 4902-4906.

Sugasawara,R.J., Cannon,J.G., Black,W.J., Nachamkin,I., Sweet,R.L. and Brooks,G.F. (1983) Infect. Immun., 42, 980-985.

Swanson,J. (1977) J. Infect. Dis., 136, S138-S143.

Swanson,J., Bergström,S., Barrera,O., Robbins,K. and Corwin,D. (1985) J. Exp. Med., 162, 729-744.

Swanson,J., Barrera,O., Sola,J. and Boslego,J. (1988) J. Exp. Med., 168, 2121-2129.

Taha,M.K., So,M., Seifert,H.S., Billyard,E. and Marchal,C. (1988) EMBO J., 7, 4367-4378.

Thongthai,C. and Sawyer,W.D. (1973) Infect. Immun., 7, 373-379.

Tjia,K.F., van Putten,J.PM., Pels,E. and Zanen,H.C. (1988) Graefe's. Arch. Clin. Exp. Ophthalmol., 226, 341-345.

Veale,D.R., Smith,H., Witt,K.A. and Marshall,R.B. (1974) J. Med. Microbiol., 8, 325-335.

Virji,M. and Everson,J.S. (1981) Infect. Immun., 31, 965-970.

Virji,M. and Heckels,J.E. (1986) J. Gen. Microbiol., 132, 503-512.

Weel,J.F.L., Hopman,C.T.P. and van Putten,J.P.M. (1991) J. Exp. Med., 173 , in press.

Received on January 18, 1991; revised on March 8, 1991 